Este libro forma parte del acervo de la Biblioteca Jurídica Virtual del Instituto de Investigaciones Jurídicas de la UNAM

\title{
EL DERECHO A MORIR Y EL DERECHO A VIVIR \\ EN EL COVID-19: LAS VIDAS DE LOS VIEJOS Y LOS ENFERMOS CRÓNICOS O TERMINALES IMPORTAN HASTA EL ÚLTIMO SUSPIRO
}

\author{
Amparo EsPinOsa Rugarcía
}

\begin{abstract}
Más que hablar de la muerte, que en realidad nadie conoce y de la que nadie ha tenido una vivencia, debemos hablar del morir.

José SARAMAGO, Las intermitencias de la muerte
\end{abstract}

\begin{abstract}
SUMARIO: I. Introducción. II. El derecho a morir y también a vivir. III. La construcción social de la muerte en tiempos del COVID-19. IV. Raymundo: la mirada de un paciente sobreviviente. V. Rodrigo: la mirada de un médico en el frente de tratamiento de pacientes graves. VI. El enfoque de los cuidados paliativos en la pandemia. VII. Llegó un monstruo y el sistema de salud no estaba preparado. VIII. Una reflexión personal. IX. Conclusiones.
\end{abstract}

\section{INTRODUCCIÓN}

El mundo nos recibe con sonrisas y un espacio acogedor para hacer nuestra llegada a la tierra lo más bondadosa posible. No suele ocurrir lo mismo con nuestra partida. Por lo menos en México. Un gran número de mexicanos son despedidos de la vida sin el espacio y los cuidados apropiados, sin medicamentos para paliar el dolor ni las suficientes opciones a para hacer una buena transición.

Es la nuestra una cultura que desatiende a sus moribundos y también a sus viejos; una cultura que celebra a los muertos pero que, paradójicamente, no habla de la muerte. El 46.3\% de los mexicanos piensa acerca de la muerte menos de una vez al año y el 30.1\% una vez al mes. Es también 
Este libro forma parte del acervo de la Biblioteca Jurídica Virtual del Instituto de Investigaciones Jurídicas de la UNAM

significativo que el 45.3\% nunca haya hablado de su muerte y que sólo un $0.8 \%$ lo haya hecho con su médico. ${ }^{1}$

En este contexto no es de extrañar que nuestro sistema de salud haya sido diseñado para una población eternamente joven e inmortal. Esto es... hasta que una feroz pandemia nos tomó por sorpresa. Entonces la muerte salió de su escondrijo, nos miró a los ojos y comenzó a manifestarse de manera despiadada. ¿Le devolveremos la mirada y haremos amistad con ella?

La normalidad es efímera, va construyéndose de manera permanente. Hoy nos toca construirla a partir del COVID-19. Un aspecto crucial de esta "nueva normalidad", como han dado en llamarla nuestras autoridades, serán cambios radicales en la manera como los mexicanos concebimos la muerte y vivimos el proceso de morir. ¿Qué otra reacción cabe cuando hemos visto al desnudo la vergonzante realidad sanitaria de nuestro país? Cuando hemos sido testigos del enorme sufrimiento que esto ha ocasionado a centenares de mexicanos y sobre todo a aquellos enfermos graves que no han tenido acceso a los fármacos necesarios para paliar su dolor y han muerto en soledad porque el acompañamiento de sus familiares les estaba vedado.

El término de cuidados paliativos - que bien puede considerarse el parámetro de referencia para conocer el nivel de atención que una sociedad brinda a sus enfermos crónicos o terminales - , ni siquiera ha permeado entre la población. El concepto resulta ajeno a la población en general ya que únicamente el $24 \%$ de la población conoce el término; incluso a un buen número de médicos y les resulta ajeno. ${ }^{2}$ Menos aún ha permeado el significado profundo y los servicios implícitos en en estos cuidados: la infraesructura hospitalaria de nuestro país es simplemente inadecuada para atender como es debido a nuestros enfermos terminales o crónicos que suelen ser, en buena medida, personas de edades avanzadas. Esta situación ha sido dolorosamente evidenciada por el COVID-19, como veremos más adelante.

Por el Derecho a Morir con Dignidad (DMD-México) es una organización civil que definió inicialmente su misión de promover el derecho a morir con dignidad a partir de la legalización de la eutanasia y el suicidio médicamente asistido. Esto ocurrió en el 2009; sin embargo, la realidad sanitaria

1 Por el Derecho a Morir con Dignidad, Encuesta nacional sobre muerte digna, México, diciembre de 2016, disponible en: https://dmd.org.mx/wp-content/uploads/2017/09/dmd-encuesta3.pdf.

2 Por el Derecho a Morir con Dignidad, Actitudes y opiniones sobre los cuidados paliativos en la Ciudad de México. México, agosto de 2019, disponible en: https://dmd.org.mx/wpcontent/uploads/2020/02/REPORTE-CUANTITATIVO-DE-CUIDADOS-PALIATIVOSFUNDACI\%C3\%93N-DMD-revisado-c.pdf. 
Este libro forma parte del acervo de la Biblioteca Jurídica Virtual del Instituto de Investigaciones Jurídicas de la UNAM

de nuestro país, desenmascarada por el COVID-19 en el 2020, nos obliga a ampliar esta perspectiva que ahora nos resulta estrecha y hasta miope, para cumplir cabalmente con nuestra misión de promover una muerte digna. En el contexto post pandemia, las actividades de DMD-México no deben reducirse a promover la legalización de la muerte médicamente asistida. Hoy deben abordar también algunos de los temas sanitarios degradantes en torno a la etapa final de la vida de los mexicanos algunos de los cuales abordaremos mas adelante.

Cuando buscamos una muerte digna, opciones como el derecho a la muerte médicamente asistida en sus modalidades de suicidio y eutanasia, son necesarias; pero también son insuficientes. Para que una muerte sea digna es preciso que todas las etapas anteriores de la vida, y principamente las finales, puedan vivirse en un entorno bondadoso de acuerdo a los requerimientos esenciales de los seres humanos. Hace falta, por ejemplo, que todas y todos tengamos acceso a fármacos que nos permitan vivir sin dolor el proceso de un enfermedad larga; que todos y todas contemos con espacios y medios materiales suficientes para florecer y decidir qué queremos hacer con nuestras vidas sin ser orillados o cohercionados por las circunstancias a optar por la vida o la muerte cuando no lo deseamos.

Las vidas de los viejos y los enfermos crónicos o terminales importan hasta el último suspiro. Sin embargo, los contextos cultural, sanitario y legal actuales no son los que se requieren para que los mexicanos vivamos las etapas finales de nuestra vida en un ambiente apropiado y para que cuando llegue el momento de partir podamos hacerlo de manera digna: la muerte es el momento de sellar nuestras vidas y eso no es cualquier cosa. Estas preocupaciones no son nuevas; han estado ahí desde siempre. Muchos estudiosos han escrito ampliamente sobre el tema. Sin embargo habían permanecido semiocultas hasta que los reflectores del COVID-19 las iluminaron y alcanzaron notoriedad.

\section{EL DERECHO A MORIR Y TAMBIÉN A VIVIR}

En las útimas semanas, entre los meses de junio y julio de 2020, uno de los temas que mayor presencia mediática ha tenido es el del viejismo o etarismo, fue puesto en el escenario en el contexto de la escasez de ventiladores. ¿Quiénes deben tener prioridad cuando los ventiladores no alcanzan? En algún momento pareció que se estaba planteando que cualquiera... menos los viejos. La reacción de gran parte de la población fue inmediata. 
Este libro forma parte del acervo de la Biblioteca Jurídica Virtual del Instituto de Investigaciones Jurídicas de la UNAM

El debate surgió con las declaraciones del gobernador americano Dan Patrick quien dijo estar dispuesto a sacrificar su vida en aras de la vida de sus nietos en caso necesario. ${ }^{3}$ Sus palabras fueron retomadas por la prensa mundial que, como suele ocurrir, las difundió con su propio aderezo perturbador traduciéndolas (en esencia) de la siguiente manera: "Las personas mayores deben (deberían) sacrificarse en beneficio de las generaciones más jóvenes."

Era como si las circunstancias del COVID-19 nos estuvieran pidiendo a los viejos de manera indiscriminada, tomados como un grupo social homogeneo... lo mismo que pedían las circunstancias de tiempos de guerra a los jóvenes: ofrendar nuestras vidas en aras de la supervivencia de los demás. O sea, si en las guerras se sacrifica los jóvenes; en tiempos del coronavirus se sacrificaría a los viejos. La ética social a todo lo que da: el pragmatismo.

El planteamiento me resultaba paradójico: los viejos mexicanos no podemos optar por la eutanasia o el suicidio médicamente asistido dado que son prácticas ilegales y, sin embargo, se nos pide (¿exige?) sacrificarnos en aras de nuestros conciudadanos jóvenes. Llevado a extremos, una negativa a aceptar nuestra suerte podría inlcuso implicar algún castigo (como les ocurría a los soldados que desertaban), que en nuestro caso consistiría, al menos, en el repudio social.

Un prominente intelectual estadounidense, el matemático y traductor Arthur Goldhammer, lamentó su destino de ocurrir una situación tal, diciendo: "Me encuentro en ese grupo de viejos cuya libertad podría ser sacrificada en aras del 'ajuste cualitativo de años vida' de las generaciones más jóvenes y las exigencias de la economía". ${ }^{4}$

El derecho a vivir con dignidad o, dicho de otra manera, el derecho a no ser forzados a morir, es el anverso de una moneda cuya otra cara es el derecho a morir con dignidad. Porque, para dar un ejemplo, como apunté al principio, parecería factible que se nos obligara a los viejos a morir en aras de los demás; aunque también se nos obliga a morir, si bien de manera indirecta, cuando por falta de atención médica eficiente y de medicamentos para paliar el dolor no nos queda otra alternativa que la muerte pues no hay quien aguante siquiera un dolor de muelas por un tiempo largo. Podemos también pensar que a los viejos se les está de hecho orillando a

3 Parker, Kathleen, "Beware insidious messaging about who lives and who dies", The Washington Post, Washington D. C., 27 de marzo de 2020, disponible en: https://wrwre.washing tonpost.com/opinions/beware-insidious-messaging-about-who-lives-and-who-dies/2020/03/27/28ecc 710-705c-11ea-aa80-c2470c6b2034_story.html.

4 Comunicación por correo electrónico de Arthur Goldhammer a Frances Kissling, 4 de mayo de 2020. 
Este libro forma parte del acervo de la Biblioteca Jurídica Virtual del Instituto de Investigaciones Jurídicas de la UNAM

morir cuando nuestra cultura los mira como material de desecho pasados los 60 años.

Desde esta perspectiva, para ser fiel a su misión de velar por los derechos humanos hasta el final de la vida, DMD decidió ampliar su horizonte; en adelante ya no sólo mirarará hacia una muerte digna vía la legalización de la eutanasia y del suicidio médicamente asistido, sino que mirará además hacia el derecho a vivir, a que nadie sea orillado a morir, por las razones que sea, si no quiere hacerlo.

Bajo este planteamiento dirigimos nuestra atención hacia lo que está pasando en esta era del coronavirus en las áreas de cuidados intensivos y paliativos de los hospitales; hacia la atención que se les está otorgando a los moribundos y en especial a los ancianos. Para hacerlo realizamos una serie de entrevistas a pacientes recuperados del COVID-19, a médicos internistas y geriatras de hospitales públicos y privados, asi como enfermeras intensivistas y de cardiología, con el fin de conocer su punto de vista.

A manera de introducción de este estudio me aproximaré a lo que que ha sido la construcción social de la muerte en tiempos del COVID para tener un marco de referencia antes de transcribir la síntesis de dos de estas entrevistas.

\section{LA CONSTRUCGIÓN SOCIAL DE LA MUERTE EN TIEMPOS DEL GOVID-19}

La muerte involucra todo lo humano; se conceptúa de acuerdo con el sistema de valores de cada persona, se relaciona con la propia historia de vida y las experiencias previas. El concepto muerte se modela también de acuerdo con estándares o perspectivas de cada grupo social, de cada época y de cada lugar. La muerte es representada en la suma de sensaciones objetivas y subjetivas personales y del colectivo. ${ }^{5}$ En las diferentes latitudes y en cada momento de la historia de la humanidad, es posible reconocer una red de significados culturales relacionados con la muerte. El concepto abarca una constelación de aprendizajes, memorias, emociones y nociones tanto en el plano individual como en el colectivo, las cuales están insertas en un contexto cultural y en las experiencias de cada individuo. ${ }^{6}$

5 Cardona, Doris y Agudelo, Héctor Byron, "Construcción cultural del concepto de calidad de vida", Revista Facultad Nacional de Salud Pública, Antioquía, enero-junio de 2005, pp. 80-90.

\footnotetext{
6 Idem.
} 
Este libro forma parte del acervo de la Biblioteca Jurídica Virtual del Instituto de Investigaciones Jurídicas de la UNAM

Los cambios sociales y ambientales modifican la construcción cultural de la muerte. Las guerras, los estados de excepción, los desastres naturales y las pandemias matizan la experiencia colectiva e individual de la fragilidad humana. Desde esta perspectiva cabe preguntarnos, ¿qué elementos han modificado nuestra experiencia de la muerte durante la pandemia de COVID-19? ¿Cuál y cómo ha sido el contexto donde están ocurriendo las defunciones?

Pasa que la oleada de muertes generada en la epidemia, la incertidumbre y la inseguridad derivados de la aparición de una nueva enfermedad intratable, la vulnerabilidad de los enfermos, la pobre capacidad resolutiva de los servicios de atención en salud, el contacto cercano con personas infectadas, los cambios de comportamiento al interior de la comunidad, entre otros, no pueden sino haber modificado el significado de vivir y de morir a nivel individual.

A partir del COVID-19 los mexicanos llevamos a cabo acciones en respuesta al miedo, a la incertidumbre y al sentimiento de impotencia ante la posibilidad de la muerte. Nos cambiamos los zapatos, lavamos nuestras manos, usamos mascarilla, desinfectamos los empaques de los alimentos, lavamos y desinfectamos las superficies de hogares y centros de trabajo, entre muchas otras. Tanto las recomendaciones de la autoridad sanitaria, las experiencias que tenemos con las personas que enferman y las modificaciones en el día a día de los lugares públicos han modificado nuestros comportamientos sociales, también están matizando nuestras relaciones interpersonales y las actitudes frente a la vida y la muerte.

En un país en donde hasta hace muy poco no se hablaba prácticamente de la muerte hoy, al interior de sus hogares, las familias hablan sobre las voluntades anticipadas en caso de enfermar de gravedad y dan directrices de tratamiento en escenarios adversos. Hoy la muerte toca a las puertas y el contacto que tenemos con ella se ha vuelto recurrente y cotidiano. En el pensamiento colectivo, la muerte comienza a interiorizarse, a convertirse en una realidad y a exaltar el miedo, tan intrínsecamente humano.

Sin embargo, este contacto con la finitud no parece estar caminando hacia la resignación. A nivel comunitario, parece que más bien se da la respuesta contraria. Los líderes políticos buscan culpables, se atacan entre ellos, observan la responsabilidad de no estar preparados o la negligencia de un puñado de culpables. Los medios de comunicación dan por sentada una salida a través del desarrollo de una vacuna y se preguntan cuándo se contará con ella. ${ }^{7}$

7 Harari, Yuval N., "Will coronavirus change our attitudes to death? Quite the opposite", The Guardian, 20 de abril de 2020, disponible en: https://wrere.theguardian.com/books/2020/ apr/20/yuval-noah-harari-will-coronavirus-change-our-attitudes-to-death-quite-the-opposite. 
Este libro forma parte del acervo de la Biblioteca Jurídica Virtual del Instituto de Investigaciones Jurídicas de la UNAM

El imaginario colectivo busca sobreponerse a la adversidad: aminorar el daño en los infectados, encontrar la cura o tener la vacuna.

A diferencia de otras pandemias en la historia de la humanidad, el COVID-19 no se toma como un castigo divino o un mal inevitable. Por el contrario, se entiende como un enemigo que altera el equilibrio al que es posible vencer y a eso enfocamos todas nuestras energías. Incorporar a la muerte en la vida no parece considerarse una alternativa. El imaginario colectivo mira hacia la inmortalidad. ${ }^{8}$

Las posiciones encontradas en la construcción individual y colectiva de la muerte guardan relación con la identidad de los fallecidos. Para acercarse a la muerte hay una sola condición: la individualidad del muerto tiene que ser presente y reconocida. No hay perturbación cuando el muerto es anónimo. La afirmación de la individualidad hace la conciencia de la muerte y la creencia en la inmortalidad. El estado de guerra o las muertes que acontecen diariamente en la pandemia son un ejemplo de la disolución de la presencia de la muerte por el predominio de la afirmación social sobre la afirmación del individuo. ${ }^{9}$ La vida humana se escandaliza, se consterna frente a la muerte. Los diversos rostros de la muerte irrumpen en más de una disciplina teórica y estremecen a más de un discurso científico, religioso, político y artístico.

\section{RAYMUNDO: LA MIRADA DE UN PACIENTE SOBREVIVIENTE}

Ante este panorama, DMD México busca indagar en las circustancias concretas que lo conforman y ha realizado, como referí previamente, una serie de entrevistas a profundidad, vía telefónica y por internet. Estas entrevistas fueron audiograbadas con previa autorización de los consultados, con una duración aproximada de 60 minutos. Entrevistamos a pacientes recuperados del COVID-19, a médicos internistas y geriatras de hospitales públicos y privados, enfermeras intensivistas y de cardiología con la intención de aproximarnos a los siguientes cuestionamientos: ¿Cómo perciben los pacientes la atención sanitaria que se les ofrece? ¿Cómo se está atendiendo a los ancianos? ¿Cuáles han sido las vivencias del personal sanitario que atiende a enfermos COVID-19, de los cuales muchos fallecerán? ¿Cómo han resuelto el dilema de la escasez de material cuando se les ha presentado? ¿Bajo que condiciones está ocurriendo realmente la atención a los enfermos?

\footnotetext{
8 Idem.

9 Antaki, Ikram, "Historia de la muerte", El Banquete de Platón: Filosofia, Ciudad de México, Joaquín Mortiz, 1996, p. 115.
} 
Este libro forma parte del acervo de la Biblioteca Jurídica Virtual del Instituto de Investigaciones Jurídicas de la UNAM

A continuación presentaré los resultados más relevantes de la entrevista realizada a un hombre sobreviviente de COVID-19. Se emplean nombres ficticios para el relato.

Raymundo tiene 48 años, es abogado y labora como ejecutivo medio en una empresa particular. Enfermo recuperado del COVID-19 sin antecedentes patológicos aunque con cierto grado de sobrepeso, Raymundo fue diagnosticado en marzo de 2020 en Pachuca, Hidalgo.

Empezó con fiebre que se le quitó inexplicablemente cuando llegó por primera vez a consulta al hospital inflable de Pachuca. Le diagnostican infección en la garganta; le recetan unas inyecciones y lo mandan a casa. Vuelve al hospital, con fiebre, cinco días después. Su oxigenación no está por debajo de los reglamentarios 88, no le hacen la prueba del COVID-19 y lo regresan de nuevo a casa. Pasan tres días, Raymundo no siente mejora y empieza a perder el gusto y el olfato, por lo que vuelve al hospital... "Esta vez mi oxigenación está por debajo de los 88 y me hacen la prueba del COVID-19. Resulta positiva y me trasladan al Hospital General de Pachuca para sacarme una tomografía de torax. «Estás muy mal, te tengo que intubar; si no, no sales», me dice el médico en cuanto la ve".

Raymundo firma la autorización para el intubamiento; no hay tiempo de esperar a que lo haga algún familiar. En algún momento él pudo ver la autorización de una persona que externó su última voluntad en el sentido de que no quería ser intubado...

En la misma autorización le expresó el amor a su hija y a su familia y se despidió de ellos. Muchos dirán "qué cobarde" porque debes pelear hasta el final; pero no lo sé... yo tomé la decisión de seguir peleando porque fue una promesa que le hice a mi esposa y la respeté hasta el final... si todavía estás consciente, tú debes decidir sobre tu cuerpo aunque tu familia esté en desacuerdo con tu decisión...

Durante los 17 días que Raymundo pasó intubado, nadie pudo decirle a su esposa cómo iba evolucionando... "Los médicos todavía no se ponen de acuerdo, no le podemos dar ningún reporte", le explicaban. Un día la llamaron de urgencia para que fuera de inmediato al hospital porque Raymundo fallecería en cuestion de horas. "Me había entablado, y ni para atrás ni para adelante".

Raymundo podía escuchar todo lo que decían los médicos: "si no sube su oxigenación no lo vamos a poder sacar, no lo vamos a poder despertar"; “¿qué le vamos a administrar?”; "esto no porque le puede afectar los riñones; esto tampoco porque le afectaría los pulmones". 
Este libro forma parte del acervo de la Biblioteca Jurídica Virtual del Instituto de Investigaciones Jurídicas de la UNAM

Recuerda también los audios que le enviaban su esposa y sus hijos porque eran lo único que lo arraigaba a la vida... lo único que te mantiene en pie de lucha; sabes que ahí están, que tienes que salir para ellos.

Para este abogado de 48 años los peores momentos fueron los cinco largos días que mediaron entre la extubación y la ida a casa: "Mi cerebro seguía bajo la influencia del medicamento y de todo lo que me metieron... ese shock en mi cabeza de tratar de poner en orden mis ideas y de entender tantas cosas que pasaron... es muy complicado...".

En una ocasión una enfermera llegó para darle de comer por una sonda que le acababan de colocar sin que él supiera por qué hasta que le explicaron que intentó sacarse el tubo y se rasgó el estómago...

Es ahí donde debían decirte algo así como "ayúdanos, estate tranquilo, tu familia está esperándote; no podemos tener a nadie de tus familiares aquí porque es de alto riesgo; no pueden hablar contigo; no te puedo meter un teléfono para que hagas llamadas pero tu familia está aquí, te está esperando; tú échale ganas".

A los pacientes recuperados y a los cuidadores de pacientes les preocupan las secuelas derivadas de la enfermedad, la terapia pulmonar que necesita prolongarse para garantizar la adecuada oxigenación, la forma como el virus "se come la grasa y la masa muscular, dejándonos en los huesos" y la lenta recuperación del equilibrio tras la terapia intensiva.

Como es de esperarse, en los pacientes hospitalizados hay un miedo inminente ante la propia muerte: el dejar a los hijos y nietos "desprotegidos". El riesgo - real o fantaseado - de contagiar a los demás miembros de la familia es otro de los temores más arraigados, con la culpa concomitante que esto traería. Prevalece el miedo a perder la propia autonomía y quedar incapacitado para realizar funciones vitales como sentarse, ponerse de pie, bañarse o alimentarse por sí mismo.

Los pacientes recuperados refieren cierta hipersensibilidad y labilidad emocional: "sentimientos a flor de piel, risa y enojo exagerado y algunas discusiones maritales que tardamos más en resolver". Por otro lado, parecería que superar la crisis es un reto o una batalla bien librada, por lo que se sienten agradecidos y afortunados.

En referencia a los familiares, la espera del parte médico afuera del hospital, que en ocasiones se da por teléfono, por WhatsApp, o bien, no se da porque el médico no tiene tiempo de hacerlo, ni de explicarles cómo reintegrarse a la dinámica familiar tras el alta hospitalaria, genera una gran angustia, enojo, confusión y frustración. 
Este libro forma parte del acervo de la Biblioteca Jurídica Virtual del Instituto de Investigaciones Jurídicas de la UNAM

"Tras enfermarte, la familia te trata como leproso y a mi empleada doméstica, que también iba a casa de mis abuelos a trabajar, la trataron como perro rabioso, aunque ella nunca se contagió. Eso es lo peor; nadie trata la parte humana del COVID-19" (paciente recuperada y cuidadora, 38 años).

Pacientes recuperados que estaban empleados, reconocen que el impacto laboral, en ciertas compañías, ha sido significativo. Asimismo, les agobia que las afectaciones macroeconómicas llegarán a ser desastrosas en México.

\section{RODRIGO: LA MIRADA DE UN MÉDICO EN EL FRENTE DE TRATAMIENTO DE PACIENTES GRAVES}

Rodrigo es médico internista y geriatra del Hospital Regional 72 de Tlanepantla, hoy convertido en Centro de Referencia COVID-19; tiene además consulta privada en un hospital del sur de la ciudad:

Me ha tocado lo más grave, lo más dramático de la pandemia; todos los pacientes que yo veo no son la cara estadística, son los más enfermos... A un porcentaje alto les va muy mal. Esperábamos que hubiera pocos jóvenes... pero los pacientes que vemos son sobre todo jóvenes obesos de alrededor de 30 años; la mitad se intuba y lamentablemente el 70\% fallece.

Para este médico geriatra el sistema de salud de nuestro país nunca ha sido bueno, y ahora que se nos vino encima un monstruo, como él dice, no hay manera de salir airosos... "Aún así, creo que reaccionaron muy tarde, añade. Los médicos y empleados de mi hospital lo vimos venir desde enero; intentamos que se prepararan las cosas; pero hasta abril empezaron a abrir los ojos. Era ya demasiado tarde...”.

Para Rodrigo la mayor deficiencia de recursos se da en el área de recursos humanos; no existe el número suficiente de médicos especialistas y no están preparados para tratar el grado de gravedad que supone el COVID-19. Eso les toca a intensivistas, urgenciólogos, neumólogos...

Yo tengo la preparación de un internista pero no basta. Ahora como no hay intensivistas o urgenciólogos suficientes tienes que hacer algo y lo haces... pero imagínate ¿qué puede hacer un otorrino, un psiquiatra o un pediatra? No nos han capacitado en el manejo de los ventiladores... el virus es muy 
Este libro forma parte del acervo de la Biblioteca Jurídica Virtual del Instituto de Investigaciones Jurídicas de la UNAM

complejo y siento que se está perdiendo tiempo. Creo que gran parte de la mortalidad, es un reflejo de esta situación.

Hay tantas carencias sanitarias que la calidad viene siendo lo de menos; hay que sortear la crisis de la mejor manera posible. Son tantos los pacientes que los médicos ya no saben qué hacer y aún así, el apoyo a los pacientes depende en buena medida de su iniciativa y buena voluntad:

A los pacientes no se les permite llevar sus teléfonos... entonces yo les pregunto "¿qué quieres que le diga a tu familia?, dime un nombre para que sepan que eres tú”. Abajo igual: “¿qué quieren que les diga arriba, algún mensaje para el paciente?”. Entiendo que los pacientes estén tan aislados por eso de la infección; pero de ahí a que muchos de ellos salgan en una bolsa para ir directo al crematorio...

La decisión de intubar o no a un paciente es un tema que le preocupa tanto como los documentos de voluntad anticipada; su punto de partida es que el adulto mayor siempre ha sido discriminado...

Para nosotros los geriatras la edad del paciente nunca es el factor para decidir un tratamiento. Los urgenciólogos dicen: "A toda persona arriba de 80 con una o dos enfermedades, no la voy a intubar; son momentos de crisis y en momentos de crisis, como en la guerra, se toman decisiones"...

Yo les digo, "a ver, tranquilos, ¿cuál guerra? Esto es medicina, no somos mercenarios; somos gente de principios, tomamos decisiones en base a la ciencia, a la evidencia".

Aquí entra el tema del viejismo. Lo veo todos los días, en urgencias, en terapia intensiva... y son ahorita estos los que están tomando las decisiones: dicen que por la crisis, de 80 para arriba no los van a intubar; pero siempre ha sido así. Su viejismo no los deja ver más allá.

Rodrigo resume su entrevista diciendo que para él, el COVID-19 es un parteaguas. No es solamente un tema médico, enfatiza. Es un tema social, bioético, económico... abarca todo. Si vemos a la pandemia de manera integral, como si fuera una carrera, como un concepto que envuelve a las demás áreas, tal vez en algún momento habría un método para seguir en cada caso y no se tomarían decisiones al vapor como se han estado tomando. "En México las decisiones para enfrentar la pandemia fueron pensadas en términos económicos, como en todo el mundo; de hecho ahorita, estamos en que se reabre todo por la economía y a ver cómo nos va; son decisiones totalmente políticas y económicas, sin pensar en el virus". 
Este libro forma parte del acervo de la Biblioteca Jurídica Virtual del Instituto de Investigaciones Jurídicas de la UNAM

\section{EL ENFOQUE DE LOS GUIDADOS PALIATIVOS EN LA PANDEMIA}

Cuando tocamos el tema del derecho a vivir y morir con dignidad, vienen a nuestra mente los escenarios clínicos de las personas infectadas. El acceso a cuidados médicos de calidad en el final de la vida tiene un sinnúmero de elementos y determinantes a los que se suman la velocidad de avance y las complicaciones relacionadas con una nueva enfermedad como puede ser el COVID-19.

El acceso a los servicios de salud y a la asesoría médica en domicilio, la saturación de los servicios de atención a los enfermos, el riesgo de contagio de los familiares y del personal de salud, la asignación y disponibilidad de recursos, medicamentos e insumos, entre otros, son elementos que merman el derecho de los pacientes a acceder de forma efectiva a la paliación del dolor y al control de síntomas de agonía; inhiben también su derecho al acompañamiento de sus familiares.

Las condiciones de los servicios de salud inciden también en los derechos de los cuidadores a la protección del contagio y al apoyo emocional y psicológico. Entran en pugna asimismo el derecho del personal de salud a la toma de decisiones informadas para evitar el encarnizamiento terapéutico y asignar efectivamente los recursos disponibles al cuidado de los enfermos.

Hoy, el personal de salud se encuentra prácticamente rebasado, no solamente por la pobre disponibilidad (en la mayoría de los escenarios ausencia) de equipos multidisciplinarios para los cuidados paliativos, sino por la carga emocional que conlleva el cuidado de estos enfermos críticos. ${ }^{10}$ Las medidas de cuidado de los síntomas de sufrimiento pueden requerirse de forma urgente en los pacientes con infección por COVID-19, pero también la comunicación efectiva con la familia de los enfermos y los cuidados psicológicos del personal de salud.

De acuerdo con la Sociedad Europea de Oncología Médica, los pacientes infectados con COVID-19 tienen el derecho al alivio del sufrimiento al final de la vida. La velocidad de avance de la enfermedad en los casos graves y la comunicación sensible y efectiva con el paciente y la familia representan dos retos en la implementación de cuidados paliativos en el contexto de la pandemia. $^{11}$

10 Human Rights Watch, Care when there is no cure. Ensuring the right to palliative care in Mexico. 28 de octubre de 2014, p. 30, disponible en: http://features.hrw.org/features/HRW_2014_report/ Mexico_Care_When_There_Is_No_Cure/assets/mexico1014_web.pdf.

11 European Society for Medical Oncology, "Emergency palliation protocol for non- ventilated COVID-19 patients - inpatient version_-", Ginebra, mayo de 2020, p. 1, disponible 
Este libro forma parte del acervo de la Biblioteca Jurídica Virtual del Instituto de Investigaciones Jurídicas de la UNAM

Los cuidados del final de la vida, denominados de forma genérica cuidados paliativos, tanto en el escenario del hospital como de la casa, resultan indispensables para aliviar la incisión, el dolor y las heridas psicológicas y emocionales que deja a su paso este virus en las comunidades. Las consecuencias de no acceder a cuidados paliativos serán devastadoras en el tiempo. En ausencia de una cura y de una vacuna, estos cuidados son quizá el único camino para aliviar el sufrimiento de una pandemia como la que acontece.

El término cuidados paliativos (como vimos antes) no ha permeado aún entre la población mexicana. Incluso a un buen número de médicos le es desconocido; sus componentes y significado profundo han permeado aún menos. En nuestro país la ley al respecto - que sí existe - es prácticamente letra muerta y a la fecha ha probado ser ineficaz particularmente en lo que toca a los mexicanos física y económicamente más desprotegidos. ${ }^{12}$

Contrario a lo estipulado legalmente, las áreas geográficas de México atendidas por unidades de cuidados paliativos distan mucho de abarcar a la mayoría de la población. En el 2014 de los 32 estados de la República, 7 no contaban en absoluto con espacios de cuidados paliativos; 17 tenían sólo un servicio de cuidados paliativos en su ciudad capital y sólo la Ciudad de México contaba con servicios de cuidados paliativos auspiciados tanto por la Secretaria de Salud, el IMSS y el ISSSTE. ${ }^{13}$ Más aún, una buena parte de las escasas unidades de cuidados paliativos que operan en el país carecen de los medicamentos y los recursos humanos y técnicos suficientes para prestar sus servicios de manera satisfactoria, como también lo exige la ley.

En este contexto, la parte de la población que vive en pueblos alejados de las grandes ciudades difícilmente tendrá acceso a los fármacos esenciales para paliar el dolor que suele acompañar a una enfermedad crónica o terminal; las unidades de cuidados paliativos debidamente abastecidas para proporcionarlas están fuera de su alcance. ${ }^{14}$

Aunque las preferencias de los mexicanos se inclinan a una atención domiciliaria de cuidados paliativos, estos se ofrecen (casi exclusivamente) dentro del ámbito hospitalario. El servicio de atención paliativa en casa (prevista en nuestra legislatura), acorde a nuestra idiosincracia, es una tarea que ha quedado pendiente. La ausencia de fármacos para paliar el dolor y/o la dificultad que existe para conseguirlos es particularmente grave. Este

en: https://wrercesmo.org/covid-19-and-cancer/covid-19-full-coverage/covid-19-useful-resources/covid19-palliative-care-pathways.

12 Por el Derecho a Morir con Dignidad, Actitudes y opiniones sobre los cuidados paliativos en la Ciudad de México, op. cit.

13 Human Rights Watch, op. cit.

14 Idem. 
Este libro forma parte del acervo de la Biblioteca Jurídica Virtual del Instituto de Investigaciones Jurídicas de la UNAM

fenómeno es multifactorial y mucho se ha escrito al respecto. Una encuesta llevada a cabo por DMD-México en la Ciudad de México arroja información respecto del sentir de la población en torno a este tema. ${ }^{15}$

Al preguntar a los encuestados si conocían o habían oido hablar de algun tipo de medicamento en base a alguna droga controlada que se les suministrara a los enfermos para aliviar el dolor, el 6 de cada 10 respondieron de manera afirmativa; de estos un $37 \%$ dio como ejemplo la marihuana y el 26\% la morfina. Cuando se les preguntó su opinión sobre el uso de estos fármacos, el 81\% dijo que buena y la razón que esgrimieron para justificar su opinion es que quita el dolor; un 19\% dijo que el uso de estos fármacos es mala o muy mala porque es una droga y causa adicción. ${ }^{16}$

Pese a la opinión favorable de la mayoría de la población acerca del uso de fármacos controlados para paliar el dolor, un gran número de mexicanos y mexicanas mueren en medio de grandes dolores ante la impotencia de sus familiares de proporcionale alivio a su sufrimiento. Un estudio cualitativo que realizó DMD México para conocer las categorías asociadas al término en la población de la Ciudad de México evidenció las consecuencias del pobre acceso a los cuidados paliativos. ${ }^{17}$

Mi mamá llegó a odiar a los doctores, ya no quería saber nada de ellos. Ninguno les acompañaba en la agonía de mi abuela. Sólo le decían: "Así es esto. Así serán los dolores". En una ocasión mi abuelita, desesperada, le suplicó a mi mamá: "Ay, hijita, inyéctame algo que me lleve de aquí, ya no aguanto más".

\section{LLEGÓ UN MONSTRUO Y EL SISTEMA DE LA SALUD NO ESTABA PREPARADO}

La totalidad de los entrevistados por DMD-México coincide en que la enfermedad no se concibe en sus reales dimensiones. Ya sea por negación, por una creencia de que son omnipotentes o por pensamiento mágico, gran parte de la población sigue corriendo riesgos y vulnerando a otras personas de sus entornos. Se trata de un tema que abarca lo social, lo bioético, lo económico

15 Por el Derecho a Morir con Dignidad, "Actitudes y opiniones sobre los cuidados paliativos en la Ciudad de México", op. cit.

16 Idem.

17 Por el Derecho a Morir con Dignidad, "Estudio Exploratorio en Cuidados Paliativos", México, agosto de 2019, disponible en: https://dmd.org.mx/wp-content/uploads/2020/02/RESULTADOS-CUALITATIVOS-FUNDACI\%C3\%93N-DMD-CuidadosPaliativos-2019-c.pdf. 
Este libro forma parte del acervo de la Biblioteca Jurídica Virtual del Instituto de Investigaciones Jurídicas de la UNAM

y no sólo lo médico y lo político. Es esta perspectiva integral la que no se ha logrado abordar en México.

La actuación del gobierno federal y local tiende a calificarse entre regular y pésima, tanto por disfrazar el estado de emergencia, como por la asimetría en el reporte veraz de los casos reales y, sobre todo, por no predicar con el ejemplo. Los médicos comentan sobre todo la falta total de ética que al manejar cifras no reales que dan un panorama distinto a la población y hacen creer que el problema es menor; ellos refieren que hay temor a no tener acceso a una cama de hospital, o bien, a ser tratados por médicos que están "improvisando/ experimentando", pues carecen de experiencia en el tratamiento del virus.

El personal de salud también admite que en algunos casos se ha caído en un grado de apatía, estrés y burn out: el médico, la enfermera y el camillero utilizan un traje que simula "un sauna" y no tienen tiempo de tomar agua, ir al baño, descansar, pues "hay todo un protocolo para quitarse el traje". Es decir, su calidad de vida se ha visto mermada de modo considerable. Desde la perspectiva médica, la enfermedad arroja — día a díanuevos datos epidemiológicos, por lo que la capacidad de respuesta está limitada. Las lagunas o deficiencias que más destacan giran en torno a la prevención de los contagios y los recursos humanos.

El gobierno federal ha enviado dobles mensajes, mensajes poco contundentes o tardíos a la población, desinformándola. Asimismo, los pacientes no saben cómo aislarse dentro de casa. Los recursos humanos, pues hay una cantidad insuficiente de médicos especialistas: algunos se incapacitaron, otros desaparecieron, otros se han contagiado y, principalmente, México carece de intensivistas y urgenciólogos:

El sistema de salud está muy castigado; en mi hospital del IMSS siempre ha habido falta de medicamentos, mala logística, mala administración y ahora, ante este monstruo, no había modo de prepararse. (Médico internista y geriatra)

La saturación de hospitales es el termómetro con que se mide la gravedad, pero eso es sólo la punta del iceberg. Intubar es un arte, es una labor interdisciplinaria que no cualquiera logra. Y ahora, tiempo después, la terapista aún me enseña a respirar por el diafragma para oxigenar por arriba de 90 , y todavía uso oxígeno para dormir y bañarme. (Paciente recuperado)

Médicos y enfermeras manifiestan que ante el coronavirus no hay tiempo ni recursos tales como morfina para los cuidados paliativos ya que éstos demandan un equipo de apoyo que dé soporte y, en este caso, no es posi- 
Este libro forma parte del acervo de la Biblioteca Jurídica Virtual del Instituto de Investigaciones Jurídicas de la UNAM

ble: hay nuevos casos cada día de nuevas defunciones. Sin embargo reconocen que varios hospitales mexicanos han sido ejemplares en su capacidad de adaptación y reconversión: siguiendo el método de la OMS han dictado pautas para el flujo de pacientes, para la seguridad del personal, el traslado de pacientes, la desinfección intensiva, etc. Asimismo, se han acondicionado hospitales inflables (como el de Pachuca) para hacer frente a la contingencia.

La empatía, el cuidado y el apoyo emocional del personal de salud ha contribuido de manera fundamental en la recuperación, sobre todo entre pacientes hospitalizados que viven una sensación de abandono y soledad que valoran el vínculo con un experto, cuando las condiciones permiten entablarlo y aunque no haya ningún protocolo disponible a la fecha.

El personal de salud se siente descobijado, descorazonado; el gobierno ya va a reabrir todo y eso recaerá en nuestra carga de trabajo. El estrés nunca va a bajar mientras siga esa poca conciencia. (Médico internista y geriatra)

Yo hablo con mis compañeras, hacemos dinámicas para relajarnos, pero el médico es más apático, sólo da indicaciones y ya... Es muy duro ver los decesos de los pacientes, pero también ver que nuestros mismos compañeros se van. (Enfermera intensivista)

Es crucial admitir que no se tiene todo bajo control, como generalmente se espera. El contagio se da tan rápidamente que impide evaluar el contexto de cada paciente: su edad, su capacidad de autonomía y funcionalidad previa a la enfermedad, sus antecedentes en cuanto a enfermedades debilitantes, etc. Los hospitales y clínicas se vuelven caóticos, desorganizados y plagados de incertidumbre, dado que no hay suficientes pruebas COVID-19, el personal de salud se infecta, tiene miedo de exponerse al virus, etc. En cuanto al actuar de las autoridades gubernamentales, enmascarar la severidad de la realidad es también una grave falta a la ética.

\section{UNA REFLEXIÓN PERSONAL}

Mi abuela Manuela murió de influenza española en 1918. En 2009, tras 10 años de búsqueda, descubrí donde estaba enterrada y exhumé sus restos. Leí mucho acerca de esa pandemia que alteró la vida de mi madre porque tenía apenas 6 años cuando mi abuela, su madre murió a los 28 años de edad.

Tantos años de leer sobre pandemias y jamás se me ocurrió que me tocaría vivir algo semejante; para mí la humanidad había superado esa etapa. Con el COVID-19 me di cuenta que no era así y me sentí en el limbo. Ten- 
Este libro forma parte del acervo de la Biblioteca Jurídica Virtual del Instituto de Investigaciones Jurídicas de la UNAM

go el testamento de mi abuela firmado cuatro horas antes de que muriera donde ella escribe de su puño y letra que no aportó bienes al matrimonio y poco más. Aunque práctico para los que se quedan, al menos yo no quiero morir firmando algo semejante.

Las fotos de aquella epidemia difieren de las de ahora sólo en los trajes. Aunque ahora contamos con un sistema hospitalario, las fotos de los ataúdes y los cadáveres transportados por las calles de Puebla durante la influenza española que aparecieron en los periódicos, se parecen demasiado a las fotos que vemos por Internet de lo que ocurrió en Italia hace unas pocas semanas o de lo que está ocurriendo actualmente en México. Los dramas humanos ocurren hoy como en aquella pandemia de hace cien años. Niños y niñas siguen quedando en la orfandad, como mi madre. En este contexto cabe la pregunta, ¿cuál debe ser el papel de DMD-México ante la nueva normalidad? ¿Qué quiere la gente? ¿Cómo desearían vivir nuestros últimos momentos?

El dolor. Sobre todo el dolor. Morir sin dolor es el común denominador de las diferentes traducciones que le dan a muerte digna; quizá trabajar en aras del acceso generalizado a medicamentos económicamente accesibles que lo favorecen sería prioritario. Tal vez el espacio de cuidados paliativos bien podría ser el marco a partir del cual desarrollemos una nueva actitud ante el morir; un espacio en donde la humanidad exhiba lo mejor de sí misma... la compasión, la ternura, la bondad, la solidaridad, la tolerancia y el acompañamiento; donde la ciencia, la tecnología y los conocimientos se usen al servicio de los seres humanos y podamos ser despedidos de la vida con el mismo amor con la que fuimos recibidos. Así concebidos y definidos, los cuidados paliativos bien pueden convertirse en el mejor antídoto en contra de la deshumanización que amenaza impregnar la totalidad del entorno sanitario. Esto no significa excluir de nuestro trabajo la promoción de la legalizacion de la muerte médicamente asisitida.

¿Qué tan preparados estamos para legalizar la eutanasia sin que vaya a significar una masacre? ¿Hay protocolos para concederla? ¿Debe de haberlos en este momento? ¿Como se viven las etapas previas al fallecimiento natural? ¿Cómo se viviría si hubiera el recurso legal de la eutanasia? La respuesta mayoritariamente afirmativa a favor de la eutanasia ¿Variaría si tuviéramos cuidados paliativos de primer nivel?

Cabe recordar que una buena parte de la población mexicana entiende la expresión "muerte digna" como sinónimo de la legalización de la eutanasia y el suicidio médicamente asistido. Cuidados paliativos tienen la difícil tarea de reclamar la parte que le toca de dicho imaginario y el papel que son capaces de desempeñar en el último proceso que todos enfrentaremos 
Este libro forma parte del acervo de la Biblioteca Jurídica Virtual del Instituto de Investigaciones Jurídicas de la UNAM

en algún momento, o sea, el de nuestra muerte. Es el "morir" al que hace referencia Saramago. Se trata de llevarlo a cabo sin dolor como propuso Albert Schweitzer en Gabón. Cómo bien dice Agustín Lara en su canción "Oración Caribe", se trata a fin de cuentas de tener: "Piedad, piedad para el que sufre. Piedad, piedad para el que llora. Un poco de calor en nuestras vidas y un poco de luz en nuestra aurora". Un poco de luz y de calor en la aurora del atardecer de nuestras vidas (como se ha traducido una frase de Las noches blancas de Dostoievsky).

\section{Gonclusiones}

El sistema de salud, plagado de carencias, se ve rebasado por la carga asistencial en la pandemia de COVID-19. Las instalaciones sanitarias resultan insuficientes en calidad y cantidad. Existe poca disponibilidad de fármacos apropiados para atender a todos los que padecen dolores intensos o están en agonía.

Hay escasez de médicos intensivistas, entre otras especialidades, así como de enfermeras especializadas. Y en esta vorágine, hay poco respeto hacia los moribundos. El contagio del virus se da tan rápidamente que impide evaluar el contexto de cada paciente: su edad, su capacidad de autonomía y funcionalidad previa a la enfermedad, sus antecedentes en cuanto a enfermedades debilitantes, entre otras. Los hospitales y clínicas están caóticos, desorganizados y plagados de incertidumbre, dado que no hay pruebas COVID-19 suficientes, el personal de salud se infecta y tiene miedo de exponerse al virus.

Aunque hay guías oficiales para enfrentar la pandemia y tomar mejores decisiones, los médicos y enfermeras necesitan sentirse apoyados y resulta sumamente complejo decidir, subjetivamente, qué vida vale más que otra y quién merece un ventilador. La empatía, el cuidado y el apoyo emocional del personal de salud ha contribuido de manera fundamental en la recuperación, sobre todo entre pacientes hospitalizados que viven una sensación de abandono y soledad que valoran el vínculo con un experto, cuando las condiciones permiten entablarlo y aunque no haya ningún protocolo disponible a la fecha. 